\title{
(6) OPEN ACCESS \\ Does cessation of community water fluoridation lead to an increase in tooth decay? A systematic review of published studies
}

\author{
Lindsay McLaren, ${ }^{1}$ Sonica Singhal ${ }^{2}$
}

\begin{abstract}
- Additional material is published online only. To view please visit the journal online (http://dx.doi.org/10.1136/jech2015-206502).

1 Department of Community Health Sciences, University of Calgary, Calgary, Alberta, Canada

${ }^{2}$ Discipline of Dental Public Health, Faculty of Dentistry, University of Toronto, Toronto, Ontario, Canada
\end{abstract}

\section{Correspondence to}

Dr Lindsay McLaren,

Department of Community

Health Sciences, University of

Calgary, 3280 Hospital

Dr. NW, Calgary, Alberta,

Canada T2N 4Z6;

Imclaren@ucalgary.ca

Received 12 August 2015 Revised 28 March 2016 Accepted 13 April 2016 Published Online First 13 May 2016

\section{ABSTRACT \\ Background Cessation of community water \\ fluoridation (CWF) appears to be occurring with increasing frequency in some regions. Our objective was to comprehensively review published research on the impact of CWF cessation on dental caries.}

Methods We searched 13 multidisciplinary databases. Results were synthesised qualitatively and quantitatively. Results We identified 15 instances of CWF cessation ('intervention') in 13 countries, which covered a broad time frame (1956-2003) and diverse geographical and political/economic contexts. Overall, results were mixed, but pointed more to an increase in caries postcessation than otherwise. For example, of the 9 studies with at least moderate methodological quality based on criteria we developed for this review, 5 showed an increase in caries postcessation. 3 studies did not show an increase in caries postcessation; however, important postcessation changes (eg, implementation of alternative fluoride delivery programmes) and/or large-scale social change may have contributed to those effects. Of the 3 study groupings that permitted quantitative synthesis, 2 showed statistically significant mean overall increase in caries postcessation; however, quantitative synthesis results must be interpreted cautiously.

Conclusions Overall, the published research points more to an increase in dental caries post-CWF cessation than otherwise. However, the literature is highly diverse and variable in methodological quality. To build this literature, it is important to exploit research opportunities presented by CWF cessation. Remaining knowledge gaps include the impact of CWF cessation on the distribution of dental caries (ie, equitable or not) and understanding the decision-making circumstances around CWF cessation.

\section{INTRODUCTION}

Community water fluoridation (CWF) refers to the controlled addition of a fluoride compound to a public drinking water system for the purpose of preventing tooth decay in populations. ${ }^{1} \mathrm{CWF}$ is an excellent example of a population-level approach to prevention that is structural in nature ${ }^{2} 3$ in that it is delivered to a whole population (eg, municipality) in a way that does not require active uptake. Research that has accrued since CWF's initiation in CrossMark To cite: McLaren $\mathrm{L}$, Singhal S. J Epidemiol Community Health 2016:70:934-940.
1945 points to a benefit of CWF for prevention of tooth decay in populations; however, the quantity and quality of contemporary evidence are recognised to be limited. ${ }^{45}$

Most studies of CWF and dental caries are either cross-sectional comparisons of fluoridated and nonfluoridated communities, or they focus on CWF initiation circumstances earlier in the intervention's history. ${ }^{4} 5$ Research on cessation of CWF is less common, but is important because cessation appears to be occurring with increasing frequency in some regions. In Canada, for example, several municipalities have discontinued CWF in recent years, including Quebec City, Quebec (2008), Calgary, Alberta (2011); and Windsor, Ontario (2013). ${ }^{6} 7$ When a sizeable community decides to cease CWF, there is sometimes a domino effect whereby other nearby communities then decide to reconsider CWF. For example, following CWF cessation in Calgary, Alberta in 2011, at least seven other Alberta municipalities underwent CWF decision-making that year, with four voting to discontinue (personal communication, Alberta Provincial Dental Public Health Officer, 2011). Presently, there is no published synthesis of research on CWF cessation that communities can refer to when undertaking decision-making.

Our original objective was to review published research on any aspect of CWF cessation, including impact on dental caries and analysis of decisionmaking circumstances. However, we discovered that published research on aspects other than impact on dental caries is virtually non-existent. Therefore, our objective became: to systematically review published research on the impact of CWF cessation on dental caries. Existing systematic reviews of CWF are not comprehensive in their inclusion of cessation studies. For example, a Cochrane review ${ }^{5}$ included only one cessation study and concluded that 'there is insufficient information to determine the effect of stopping [CWF] on caries levels'. We were already aware of several additional cessation studies excluded from that review, and believe there is considerable value in identifying, appraising and synthesising the available literature more comprehensively.

\section{METHODS}

We considered published research on the impact of CWF cessation (intervention) in populations of any age in any jurisdiction worldwide (participants). Studies could have a comparison community, or use a historical comparison approach (comparison). We considered any study design; however, synthesis focused on studies with a pre-post design, with or without comparison community. We recorded all outcomes (eg, decayed, missing, filled teeth (DMFT), fluorosis, plaque fluoride levels); however, synthesis focused on summary caries measures at the tooth level or tooth surface level (eg, DMFT/S, deft/s). Presentation of methods and 
results follows the Preferred Reporting Items for Systematic Reviews and Meta-Analyses (PRISMA) checklist. ${ }^{8}$

We searched the following databases, from their start date to 29 September 2014: MEDLINE, PubMed, Embase, Global Health, CINAHL, ERIC, Aqualine, Biosis Previews, Education Research Complete, Environment Complete, PAIS, Public Affairs Index and SocIndex. We imposed no date or language restrictions. Details of the search, which was run by a professional health sciences librarian, are shown in online supplementary appendix A. The search was validated using publications already known to the authors. We consulted the reference lists of published systematic reviews on $\mathrm{CWF}^{4} 5$ and of a recent book that opposes CWF with an extensive reference list. ${ }^{9}$ We consulted the reference lists of included articles, and performed cited reference searches to ensure that we had all publications for each intervention.

We included empirical studies of deliberate cessation of CWF. We excluded the following: studies of unintended interruptions to CWF; commentaries and other non-empirical reports; and studies that focused on a specific subpopulation (eg, patients in one dental practice).

Titles and abstracts were reviewed twice by LM, and initial exclusions were verified by SS. Potentially relevant publications were retrieved in full text. Decision for inclusion/exclusion at the full-text stage was made independently by the two authors, based on the criteria above. Disagreements were resolved via discussion. Non-English language articles deemed potentially relevant were professionally translated. For the final set of interventions included, the following information was extracted by each author independently, with disagreements resolved via discussion: population (geographic location, age, outcome indicators); intervention (cessation time frame and circumstances); comparison community (when applicable); main findings/conclusions and study design.

We assessed the methodological quality of each intervention using an adapted version of the Cochrane Collaboration's tool for assessing risk of bias. ${ }^{5}$ The assessment was performed independently by the two authors, with disagreements resolved via discussion. The bias domains and definition of low risk of bias (ROB), were:

- Sampling: low $\mathrm{ROB}=$ random (simple or complex) sampling or all eligible children invited to participate.

- Confounding: low $\mathrm{ROB}=$ account for at least two of three important confounders identified a priori: other fluoride sources, socioeconomic status, dietary factors.

- Blinding of outcome assessment: low $\mathrm{ROB}=$ incorporation of blind outcome assessment (eg, radiographs where assessor was blind to community water fluoridation status).

- Completeness of outcome data: low $\mathrm{ROB}=$ data presented for all, or majority (at least 70\%) of participants.

- Risk of selective outcome reporting: low $\mathrm{ROB}=$ outcome of interest reported in usable format.

- Other bias: low $\mathrm{ROB}=$ no other apparent bias.

Since all interventions had at least one 'high' rating (and therefore would score 'high' ROB overall), we considered the proportion of bias domains with 'high' or 'unclear' ROB for each intervention, to permit some variation among our studies.

To synthesise results, we first grouped interventions according to whether they reported an increase in caries following cessation or not, and considered the characteristics of each group (qualitative synthesis).

Second, we performed quantitative synthesis, focusing on four outcomes: DMFT, deft, DMFS and defs. For each outcome, we considered separately (1) studies with no comparison community and (2) studies with a comparison community. Overall, this led to formulation of eight outcome-study type combinations. ${ }^{\mathrm{i}}$ A spreadsheet was created to record data (mean, SD, ${ }^{\text {ii }}$ sample size) for all possible pre-post comparisons (ie, before vs after cessation, for any age group, for any period of time postcessation) for the interventions included in that outcome-study type combination. For studies with a comparison community, we imputed the SD for the change score (post-pre) following guidelines from the Cochrane collaboration, ${ }^{10}$ using a correlation coefficient of 0 .

For the studies with no comparison community (ie, historical control), the comparison of interest was the difference between the postcessation and precessation means (ie, mean change) in the cessation community, for each caries outcome available. For the studies with a comparison community, the comparison of interest was the difference between the postcessation-precessation mean change in the cessation community, and the postcesation-precessation mean change in the comparison community, for each caries outcome.

Of the large number of comparisons considered, many were not usable because one or more of mean, SD and $n$ were missing and could not be computed. Therefore, quantitative synthesis focused on the subset with non-missing information. For that subset, we estimated overall mean effects of cessation on summary caries measures (DMFT, deft, DMFS, defs) based on a random effects model, using MIX open-source meta-analytic software. ${ }^{11}$ Several studies included observations of multiple age groups and multiple time points. Within each study, we considered different age groups as independent observations, and different time points for the same-age participants as non-independent observations. ${ }^{12}$ We computed pooled estimates across time points within age groups, following the procedures outlined in the Cochrane handbook, ${ }^{13}$ and performed meta-analysis of those pooled estimates. However, because some studies contained many more age groups than others, and therefore contributed more data to the meta-analysis, we also performed the meta-analysis using a single overall pooled estimate computed across age groups and time points for each study.

\section{RESULTS}

\section{Search results}

The databases returned 1523 unique (3809 total) citations (see figure 1 and see online supplementary appendix A). A total of 1471 were excluded as irrelevant based on title/abstract. A total of 65 full-text articles were reviewed, of which 36 were excluded for three main reasons: no substantive material about CWF cessation; a focus on defluoridation technology to reduce high levels of naturally occurring fluoride in water and a focus on unintended interruption of CWF.

We ultimately considered 15 instances of cessation (interventions) occurring in 13 countries, described in 29 publications, ( ${ }^{14-42}$ see figure 1 and see online supplementary appendix B), four of which ${ }^{28} 293538$ were professionally translated. The number of publications per intervention ranged from 1 to 4 , and the publication year ranged from 1962 to 2014 .

${ }^{\mathrm{i} D M F T}$ : no comparison community; DMFT: comparison community; deft: no comparison community; deft: comparison community; DMFS: no comparison community; DMFS: comparison community; defs: no comparison community; defs: comparison community.

ii If SE was provided, we computed SD using the formula: $\mathrm{SD}=\mathrm{SE} * \operatorname{SQRT}(\mathrm{n})$. 


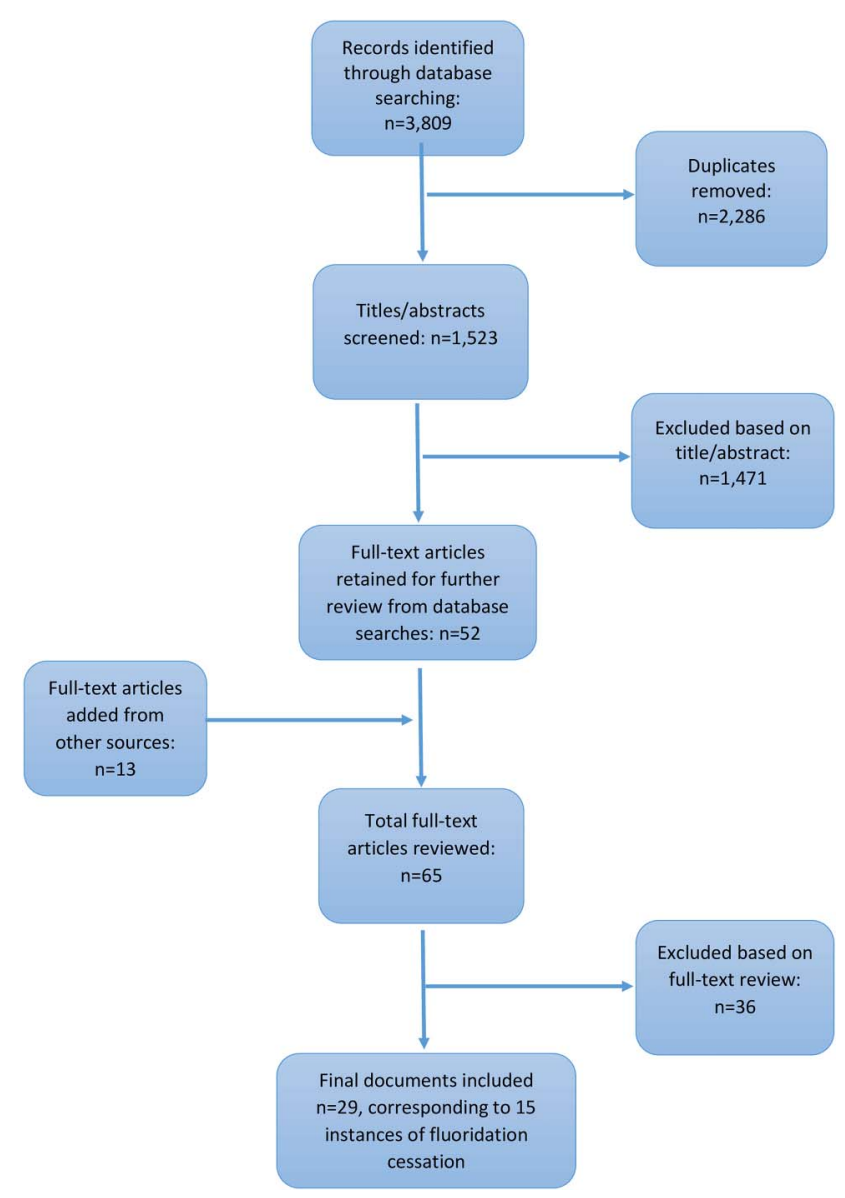

Figure 1 Study flow chart.

\section{Intervention characteristics}

The year of cessation ranged from $1956^{42}$ to $2003 .{ }^{14}$ Of the 15 interventions, one occurred in the $2000 \mathrm{~s} ;{ }^{14}$ five in the $1990 \mathrm{~s} ;{ }^{15} 19242627$ four in the $1980 \mathrm{~s} ;{ }^{28} 303435$ three in the $1970 \mathrm{~s} ;{ }^{37} 3840$ one in the $1960 \mathrm{~s}^{41}$ and one in the $1950 \mathrm{~s}^{42}$ The interventions varied in geographic location (North America, South America, Europe, Asia and the Caribbean) and in political and economic circumstances (eg, both market and mixed economies, at the time of cessation).

All interventions focused on children, age range 3 years ${ }^{18} 35$ to 15 years $^{25} 3238$ or grade 12 (approximate age 17-18 years). ${ }^{19}$ One intervention ${ }^{40}$ recruited a sample of young adults (age 18-22 years), but the interest was in their exposure to CWF as children (first 5-9 years of life).

Reasons for CWF cessation varied, and in general, limited information was provided. Based on that limited information, stated reasons for cessation included: technical issues such as ageing infrastructure, ${ }^{23} 29{ }^{30}$ significant political/economic event, $^{25} 27$ lack of clarity about pertinent laws, ${ }^{31}$ observed increases in dental fluorosis, ${ }^{35}$ opposition or antifluoridation movements, ${ }^{14} 15$ and public vote in favour of cessation. ${ }^{19}$

Six of the 15 interventions included assessments of both primary and permanent teeth. ${ }^{14} \begin{array}{llllll}17 & 28 & 32 & 35 & 36 & 41 \\ \text { Six included }\end{array}$ permanent teeth only; ${ }^{19} 2627384042$ and two included primary teeth only. ${ }^{24} 37$ One intervention ${ }^{30}$ focused on fluoride concentrations in plaque.

Of the 14 interventions that included dental caries outcomes (ie, excluding the intervention in Brazil ${ }^{30}$ ), eight included both tooth-level and tooth surface-level data ${ }^{14} 27373840$ or surface- level data only, ${ }^{16} 1935$ and six included tooth-level data only. $^{23} 25 \quad 28344142$ Use of surface-level data is thought to be preferable if the aim is to evaluate a prevention initiative ${ }^{43}$ such as cessation of CWF, against the backdrop of a general decline in prevalence of caries. ${ }^{44}$ There is a slight tendency towards more frequent inclusion of surface-level assessments with more recent interventions, but the tendency is not strong (eg, of the five most recent interventions, three include surface-level assessments). In all interventions, it appears that dental exams were performed by dental professionals (eg, dentists) following standard assessment criteria, ${ }^{43}$ although some interventions provided limited details. ${ }^{42}$

\section{Intervention findings}

Although all 15 interventions focused on CWF cessation, certain differences must be taken into consideration. First, the studies in South Korea ${ }^{14}$ and Japan ${ }^{40}$ used CWF cessation as a way to study the impact of past exposure to CWF on current dental caries. Both studies support an enduring benefit of CWF. Cho et $a l^{14}$ showed that children exposed to CWF for their first 4 years of life had lower DMFT at age 8 years, compared to those with no CWF. Since permanent teeth do not begin to erupt until age 6-7 years, these results support a beneficial systemic (pre-eruptive) effect of CWF on dental caries. Kobayashi et $a l^{40}$ found that students exposed to CWF as children had better dental health outcomes as young adults than those who had not been exposed. These two studies used a single postcessation cross-sectional design, which does not permit evaluation of the effects of cessation per se (a pre/post or longitudinal design is needed).

Second, the intervention in Brazil ${ }^{30}$ needs to be considered separately because it did not include dental caries assessment. These authors observed that fluoride concentration in plaque was significantly lower 2 months after cessation compared to during CWF. The dental caries implications of that change are not known.

\section{Qualitative synthesis}

For qualitative synthesis, we classified the 12 remaining interventions according to whether the overall conclusion indicated an increase in dental caries postcessation or not. We then considered the characteristics of those groupings, including methodological quality (see online supplementary appendix C provides ROB assessment for all 15 interventions).

Interventions that showed an increase in dental caries post-CWF cessation

Eight interventions 2328343637394142 showed an increase in dental caries post-CWF cessation. These interventions varied in time frame of cessation (range from $1956^{42}$ to $1991^{23}$ ), geography (Europe; Asia; North America) and social-political context (both market and mixed economies).

There was notable variation in the methodological quality of these interventions (see online supplementary appendix C). The highest quality (lowest ROB) interventions are those in SW Scotland, ${ }^{34}$ Wick Scotland ${ }^{37}$ and Tiel, the Netherlands; ${ }^{39}$ which scored as 'high' or 'uncertain' ROB on only one or two of six bias domains, and 'low' ROB on the others. Three interventions (former Czechoslovakia, ${ }^{28}$ China $^{36}$ and Minnesota, USA $^{42}$ ) had significant methodological problems, scoring as 'high' or 'uncertain' ROB on five of six domains (for Minnesota, ${ }^{42}$ this, in part, reflected the very brief nature of the report). The remaining two interventions (Wales ${ }^{23}$ and Wisconsin, USA, ${ }^{41}$ ) scored in the 
middle range for ROB ('high' or 'uncertain' ROB on three of six domains).

In sum, of the eight interventions that reported an increase in dental caries post-CWF cessation, five had at least moderate methodological quality, which we operationalised as scoring 'high' or 'uncertain' for three or fewer of six bias domains. Most frequent concerns among those five interventions were: insufficient accounting for potentially important confounders; lack of blind outcome assessment; and in two cases, absence of a comparison community.

\section{Interventions that did not show an increase in dental caries} post-CWF cessation

Three interventions ${ }^{18} 2627$ did not show an increase in dental caries post-CWF cessation. Cessation in these instances spanned a short time frame (range $1990^{27}$ to $1992^{18}$ ). Interventions in the former East Germany ${ }^{26}$ and $\mathrm{Cuba}^{27}$ took place in contexts characterised by socialist government and planned/mixed economies. Though Finland ${ }^{18}$ had some Soviet influence at the time, it maintained a market economy.

All three interventions had moderate methodological quality based on scoring 'high' or 'uncertain' ROB on three of six bias domains (see online supplementary appendix C). In all three cases, concerns were: insufficient accounting for potentially important confounders; lack of blind outcome assessment and other concerns about internal validity due to uncertainty about CWF exposure or absence of comparison community.

Importantly, in all three interventions, there were other factors which could have contributed to findings observed. In Finland, ${ }^{18}$ the CWF-cessation community started to provide fluoride tablets to children postcessation. In East Germany, ${ }^{26}$ postcessation fissure sealants were paid for by statutory health funds. In $\mathrm{Cuba}^{27}$ postcessation, all children received fluoride mouth rinses fortnightly, and children aged 2-5 years received 1-2 fluoride varnish applications annually. Those initiatives could have offset an impact of cessation on dental caries.

\section{Remaining intervention}

The one remaining intervention (British Columbia, Canada, ${ }^{19}$ ) was sufficiently complex in its findings that we could not satisfactorily include it in either group above. Specifically, this study used the D1D2MFS index and included two components: a repeated cross-sectional survey to observe prevalence and a prospective longitudinal investigation for recording incidence of dental caries. Those two study components showed different results. Based on the repeated cross-sectional component of the research, a reduction in mean D1D2MFS score was observed in the cessation community but no change was observed in the comparison (still fluoridated) community. ${ }^{19}$ In the prospective longitudinal component (which included lifelong residents only), the transition in smooth and pit and fissure caries between the two communities was observed. Children were classified into three groups depending on the change in extent of their tooth surface caries: progressed, reversed or unchanged between baseline and follow-up. Among these children, authors observed that caries progression, especially on smooth surfaces, was more frequent in the cessation community compared to the comparison (still-fluoridated) community. ${ }^{20}$ The two communities had similar exposures to other forms of fluoride, such as fluoridated toothpaste, good oral hygiene and access to oral healthcare. The use of sealants was also high in both sites, though higher in the cessation community. This intervention had moderate methodological quality based on our criteria, scoring 'high' or 'uncertain' on three of six bias domains (see online supplementary appendix C).

Table 1 Summary of quantitative synthesis to estimate overall mean effect of CWF cessation on DMFT, deft, DMFS, defs, based on estimates pooled across time points within age groups within each study

\begin{tabular}{|c|c|c|c|}
\hline Outcome/study type & $\begin{array}{l}\text { Total number of } \\
\text { studies } \\
\text { and comparisons }\end{array}$ & $\begin{array}{l}\text { Eligible number of studies } \\
\text { and comparisons }\end{array}$ & $\begin{array}{l}\text { Results/Comments } \\
\text { Mean (SD) } \\
\text { Number of participants ( } n \text { ) }\end{array}$ \\
\hline $\begin{array}{l}\text { DMFT-no-comparison } \\
\text { community }\end{array}$ & $\begin{array}{l}\text { Studies: } \mathrm{n}=6 \\
\text { Comparisons: } \mathrm{n}=52\end{array}$ & $\begin{array}{l}\text { Studies: } \mathrm{n}=3\left(\text { Cuba }_{i}^{27} \text { Czechoslovakia; }^{28} 29\right. \\
\text { East Germany }{ }^{25} 26 \text { ) } \\
\text { Comparisons: } \mathrm{n}=18\end{array}$ & $\begin{array}{l}\text { Significant decrease in DMFT postcessation: }-1.02 \\
(-1.42,-0.62), n=9503\end{array}$ \\
\hline $\begin{array}{l}\text { DMFT-comparison } \\
\text { community* }\end{array}$ & $\begin{array}{l}\text { Studies: } \mathrm{n}=3 \\
\text { Comparisons: } \mathrm{n}=38\end{array}$ & $\begin{array}{l}\text { Studies: } n=3\left(\text { Stranraer, Scotland }{ }^{31-34} \text { Netherlands; }^{38} 39\right. \\
\text { East Germany }{ }^{25} 26 \text { ) } \\
\text { Comparisons: } n=27\end{array}$ & $\begin{array}{l}\text { Significant increase in DMFT postcessation: } 0.54 \\
(0.24,0.84), n=111436\end{array}$ \\
\hline $\begin{array}{l}\text { deft-no-comparison } \\
\text { community }\end{array}$ & $\begin{array}{l}\text { Studies: } n=5 \\
\text { Comparisons: } n=15\end{array}$ & $\begin{array}{l}\text { Studies: } n=2 \text { (Wick, Scotland }{ }^{37} \text { China }^{35}{ }^{36} \text { ) } \\
\text { Comparisons: } n=10\end{array}$ & $\begin{array}{l}\text { Significant increase in deft postcessation: } 0.49(0.11 \text {, } \\
0.87), n=3947\end{array}$ \\
\hline deft-comparison community* & $\begin{array}{l}\text { Studies: } \mathrm{n}=2 \\
\text { Comparisons: } \mathrm{n}=5\end{array}$ & $\begin{array}{l}\left.\text { Studies: } n=1 \text { (Stranraer, Scotland }{ }^{31-34}\right) \\
\text { Comparisons: } n=2\end{array}$ & Overall effect not estimated (only 1 study) \\
\hline $\begin{array}{l}\text { DMFS-no-comparison } \\
\text { community }\end{array}$ & $\begin{array}{l}\text { Studies: } n=1 \\
\text { Comparisons: } n=4\end{array}$ & $\begin{array}{l}\text { Studies: } n=1\left(\mathrm{Cuba}^{27}\right) \\
\text { Comparisons: } n=4\end{array}$ & Overall effect not estimated (only 1 study) \\
\hline $\begin{array}{l}\text { DMFS-comparison } \\
\text { community* }\end{array}$ & $\begin{array}{l}\text { Studies: } \mathrm{n}=3 \\
\text { Comparisons: } \mathrm{n}=19\end{array}$ & $\begin{array}{l}\text { Studies: } n=3 \text { (Finland; }{ }^{16}{ }^{18} \text { Canada }^{19}{ }^{20} \text { Netherlands }^{38} \text { ) } \\
\text { Comparisons: } n=13\end{array}$ & $\begin{array}{l}\text { Overall effect estimated but not interpreted because } \\
\text { studies include both positive and negative controls } \dagger\end{array}$ \\
\hline $\begin{array}{l}\text { defs-no-comparison } \\
\text { community }\end{array}$ & $\begin{array}{l}\text { Studies: } \mathrm{n}=1 \\
\text { Comparisons: } \mathrm{n}=2\end{array}$ & $\begin{array}{l}\text { Studies: } n=1\left(\text { Wick, Scotland }{ }^{37}\right) \\
\text { Comparisons: } n=2\end{array}$ & Overall effect not estimated (only 1 study) \\
\hline defs-comparison community* & $\begin{array}{l}\text { Studies: } \mathrm{n}=1 \\
\text { Comparisons: } \mathrm{n}=6\end{array}$ & $\begin{array}{l}\text { Studies: } n=1\left(\text { Finland }^{17}{ }^{18}\right) \\
\text { Comparisons: } n=3\end{array}$ & Overall effect not estimated (only 1 study) \\
\hline Total & Comparisons: $n=141$ & Comparisons: $n=83$ & \\
\hline
\end{tabular}

Comparison=any pair of precessation - postcessation data (any time frame, any age group); total=141.

Studies=intervention (instance of CWF cessation); total $n=12$.

Eligible studies/comparisons=contained non-missing (or non-imputable) data on mean, SD, and sample size (n).

DMFT, deft=decayed, missing, filled teeth (permanent, primary).

DMFS, defs=decayed, missing/extracted, filled tooth surfaces (permanent, primary)

Results are from random effects model.

${ }^{*}$ SD for change score was imputed, following Cochrane collaboration procedure ${ }^{10}$.

tPositive control: comparison community has CWF in place; negative control: comparison community does not have CWF in place. 
Table 2 Numeric values contributing to summary estimates shown in table 1, for those studies with sufficient data for quantitative synthesis, based on estimates pooled across time points within age groups within each study

\begin{tabular}{|c|c|c|c|c|c|c|c|c|}
\hline \multicolumn{9}{|c|}{ Outcome: DMFT-no-comparison community } \\
\hline Study & $\begin{array}{l}\text { Year of } \\
\text { cessation }\end{array}$ & Age and number of years postcessation & Precessation mean & Precessation SD & Precessation $\mathrm{n}$ & Postcessation mean & Postcessation SD & Postcessation $\mathrm{n}$ \\
\hline \multirow{4}{*}{ La Salud, Cuba ${ }^{27}$} & \multirow{4}{*}{1990} & age $6 / 7 ; 7$ years $(1997)$ & 0.07 & 0.34 & 107 & 0.07 & 0.31 & 82 \\
\hline & & age $8 / 9 ; 7$ years $(1997)$ & 0.50 & 1.04 & 159 & 0.60 & 0.98 & 123 \\
\hline & & age $10 / 11 ; 7$ years $(1997)$ & 1.10 & 1.51 & 126 & 0.80 & 1.21 & 104 \\
\hline & & age $12 / 13 ; 7$ years $(1997)$ & 2.10 & 2.11 & 78 & 1.10 & 1.75 & 105 \\
\hline Prague, Czech Republic $^{2829}$ & 1988 & age $6 ; 7$ years $(1995)$ & 0.13 & 0.02 & 510 & 0.32 & 0.03 & 551 \\
\hline \multirow{6}{*}{$\begin{array}{l}\text { East Germany } \\
\text { (Spremberg) }^{25} 26\end{array}$} & \multirow{6}{*}{1990} & age $8 ; 3$ and 6 years (1993 and 1996) & 0.81 & 1.239 & 1028 & 0.44 & 0.903 & 382 \\
\hline & & age $9 ; 3$ and 6 years (1993 and 1996) & 1.10 & 1.369 & 1006 & 0.61 & 1.098 & 449 \\
\hline & & age $12 ; 3$ and 6 years (1993 and 1996) & 3.99 & 2.559 & 856 & 2.16 & 2.029 & 412 \\
\hline & & age $13 ; 3$ and 6 years (1993 and 1996) & 4.92 & 3.038 & 766 & 2.25 & 2.131 & 507 \\
\hline & & age $15 ; 3$ and 6 years (1993 and 1996) & 6.89 & 3.586 & 454 & 4.04 & 3.233 & 404 \\
\hline & & age $16 ; 3$ and 6 years (1993 and 1996) & 7.62 & 4.064 & 354 & 4.68 & 3.284 & 419 \\
\hline East Germany (Zittau) $)^{26}$ & 1993 & age $12 ; 3$ years $(1996)$ & 2.47 & 2.06 & 337 & 1.96 & 1.96 & 184 \\
\hline \multicolumn{9}{|c|}{ Outcome: DMFT-comparison community* } \\
\hline Study & $\begin{array}{l}\text { Year of } \\
\text { cessation }\end{array}$ & $\begin{array}{l}\text { Age and number of years } \\
\text { postcessation }\end{array}$ & $\begin{array}{l}\text { Post-pre (cessation } \\
\text { community): mean }\end{array}$ & $\begin{array}{l}\text { Post-pre (cessation } \\
\text { community): SD }\end{array}$ & $\begin{array}{l}\text { Post-pre (cessation } \\
\text { community): } \mathbf{n}\end{array}$ & $\begin{array}{l}\text { Post-pre (comparison } \\
\text { community): mean }\end{array}$ & $\begin{array}{l}\text { Post-pre (comparison } \\
\text { community): mean }\end{array}$ & $\begin{array}{l}\text { Post-pre (comparison } \\
\text { community): mean }\end{array}$ \\
\hline Stranraer, Scotlandt $\mathrm{t}^{31-34}$ & 1983 & age $10 ; 3$ and 5 years (1986 and 1988$)$ & 0.34 & 2.44 & 546 & -0.67 & 3.20 & 501 \\
\hline Tiel, Netherlands $\ddagger^{3839}$ & 1973 & $\begin{array}{l}\text { age } 15 ; 6-7,8-9,10-11,12-13,14-15 \text { years } \\
\text { (1979-80; 1981-82; 1983-84; 1985-86; 1987- } \\
\text { 88) }\end{array}$ & -0.75 & 6.08 & 3191 & -6.59 & 7.23 & 2538 \\
\hline Chemnitz, East & \multirow[t]{10}{*}{1990} & age $6 ; 1$ and 5 year2 $(1991,1995)$ & -0.02 & 0.66 & 8492 & 0.00 & 0.66 & 1974 \\
\hline \multirow{9}{*}{ Germany ${ }^{25} 26 \S$} & & age $7 ; 1$ and 5 year2 $(1991,1995)$ & -0.11 & 1.01 & 8492 & 0.00 & 1.30 & 1974 \\
\hline & & age $8 ; 1$ and 5 years $(1991,1995)$ & -0.27 & 1.26 & 8492 & -0.18 & 1.59 & 1974 \\
\hline & & age $9 ; 1$ and 5 year2 $(1991,1995)$ & -0.30 & 1.73 & 8492 & -0.04 & 1.95 & 1974 \\
\hline & & age $10 ; 1$ and 5 year2 $(1991,1995)$ & -0.26 & 2.27 & 8492 & 0.06 & 2.20 & 1974 \\
\hline & & age $11 ; 1$ and 5 year2 $(1991,1995)$ & -0.37 & 2.83 & 8492 & -0.24 & 2.57 & 1974 \\
\hline & & age $12 ; 1$ and 5 year2 $(1991,1995)$ & -0.37 & 2.99 & 8492 & -0.21 & 3.06 & 1974 \\
\hline & & age $13 ; 1$ and 5 year2 $(1991,1995)$ & -0.57 & 3.52 & 8492 & -0.59 & 3.66 & 1974 \\
\hline & & age $14 ; 1$ and 5 year2 $(1991,1995)$ & -0.53 & 4.07 & 8492 & -0.80 & 4.22 & 1974 \\
\hline & & age $15 ; 1$ and 5 year2 $(1991,1995)$ & -0.75 & 4.42 & 8492 & -1.77 & 4.74 & 1974 \\
\hline \multicolumn{9}{|c|}{ Outcome: deft-no-comparison community } \\
\hline Study & $\begin{array}{l}\text { Year of } \\
\text { cessation }\end{array}$ & $\begin{array}{l}\text { Age and number of years } \\
\text { postcessation }\end{array}$ & Precessation mean & Precessation SD & Precessation $\mathrm{n}$ & Postcessation mean & Postcessation SD & Postcessation $n$ \\
\hline Wick, Scotland $\mathrm{d}^{37}$ & 1979 & age 5/6; 5 years ( \pm radiograph) & 2.89 & 2.57 & 212 & 4.11 & 1.927 & 252 \\
\hline \multirow[t]{4}{*}{ China 3536} & \multirow[t]{4}{*}{1983} & age $3 ; 2.5$ and 4.5 years $(1986,1988)$ & 1.33 & 0.17 & 448 & 2.496 & 0.354 & 211.000 \\
\hline & & age $4 ; 2.5$ and 4.5 years $(1986,1988)$ & 2.36 & 0.19 & 626 & 3.290 & 0.277 & 328.000 \\
\hline & & age $5 ; 2.5$ and 4.5 years $(1986,1988)$ & 2.47 & 0.17 & 524 & 3.485 & 0.285 & 420.000 \\
\hline & & age $6 ; 2.5$ and 4.5 years $(1986,1988)$ & 3.07 & 0.21 & 498 & 3.305 & 0.298 & 428.000 \\
\hline
\end{tabular}




\section{Quantitative synthesis}

Results of the quantitative synthesis are summarised in table 1, and details of the included studies are shown in table 2. Of the eight outcome-study type combinations, five were not usable for quantitative synthesis because, once missing data were taken into account (ie, no SD and/or n provided), there was only one intervention remaining in that grouping, or, the included studies had both positive (still fluoridated) and negative (never fluoridated) comparison communities, making interpretation difficult. The remaining three outcome-study type combinations (ie, DMFT-no-comparison community, DMFT-comparison community and deft-no-comparison community) contained data from more than one intervention and/or (in the case of DMFT-comparison community) the fluoridation status of the comparison community was the same, and these were deemed suitable for inclusion in quantitative synthesis.

When we pooled estimates across time points within age groups, findings were as follows: for DMFT based on studies without a comparison community, there was a statistically significant mean decrease in DMFT postcessation $(-1.02(-1.42,-0.62)$ based on three studies, ${ }^{26-29} \mathrm{n}=9503$ participants). For DMFT based on studies with a comparison community, there was a statistically significant mean increase in DMFT postcessation $(0.54(0.24,0.84)$ based on three studies, ${ }^{25} 2631-343839 \mathrm{n}=111436$ participants). For deft based on studies without a comparison community, there was a statistically significant mean increase in deft postcessation $(0.49$ (0.11, 0.87), based on two studies, ${ }^{35-37} \mathrm{n}=3947$ participants). When we pooled estimates across age groups and time points for each study, the direction of effect was the same as above, but effects were only statistically significant in one instance: deft based on studies without a comparison community $(0.99(0.70,1.28))$ and not the others (DMFT based on studies without a comparison community: $-0.36(-1.04,0.32)$, and DMFT based on studies with a comparison community: $2.29(-1.04,5.61))$. Heterogeneity was very high in all three groupings of studies $\left(\mathrm{I}^{2}=99.2 \%, 99.8 \%\right.$ and $99.1 \%$, respectively), and none of these groupings represents the full sample of studies identified through our search.

\section{DISCUSSION}

Overall, published research on CWF cessation and dental caries points more to an increase in dental caries postcessation than otherwise. Specifically, of the nine interventions that directly examine the impact of CWF cessation on dental caries (ie, excluding interventions in South Korea, ${ }^{14} \mathrm{Japan}^{40}$ and Brazil ${ }^{30}$ ), and that have at least moderate methodological quality (which we operationalised as 'high' or 'unclear' ROB on three or fewer of six bias domains), five showed an increase in caries postcessation, ${ }^{3437392341}$ three did not ${ }^{18} 2627$ and the findings of one ${ }^{19}$ were mixed. The results of the quantitative synthesis support this conclusion: of the three outcome/study-type groupings that provided sufficient data for quantitative synthesis, two point to a significant increase in caries postcessation (though one was reduced to non-significance when we pooled the data to the study level). However, the quantitative synthesis results must be interpreted cautiously because of the small proportion of studies included, our use of imputation for SDs for the comparative studies, and the significant heterogeneity across studies.

An overall conclusion, furthermore, masks nuance between the interventions. Findings from three interventions, which had moderate methodological quality according to our criteria, did not show an increase in dental caries postcessation. Those findings suggest that adverse outcomes are not uniform or inevitable. In those three jurisdictions, ${ }^{18} 2627$ there was postcessation implementation of preventive measures such as supplemental fluoride and funding for dental sealants. Those measures may represent viable alternatives for communities postcessation. However, important factors must be considered, including: the context (is a universal system for supplemental fluoride delivery in place or feasible?), equity (is the impact of fluoride alternatives borne equitably across the population?) and cost-effectiveness (even if the alternative fluoride delivery mechanisms are beneficial, are they costeffective?). The similarities across these three interventions (Finland, East Germany, Cuba) in time frame (all early 1990s) and sociopolitical and economic circumstances, raises important questions about whether the same effects could be expected in contemporary market economies with wide and growing income inequalities. ${ }^{45}$ These are important questions for future research.

Owing to the comprehensiveness of our search, we were able to identify other knowledge gaps. First, there is very limited published research on decision-making circumstances around CWF cessation. We found only two brief papers. ${ }^{46} 47$ Second, evidence on the equity implications of discontinuing CWF is absent: none of our studies examined equity of impact. Third, all our studies focused on children; there may be value in studying the impact of CWF cessation on other demographic groups such as seniors.

One limitation is our exclusive focus on published research. We did not contact authors to identify unpublished studies; accordingly, we may have missed relevant work in the grey literature such as health authority reports. Strengths of our review include the systematic and comprehensive search for all studies on the subject, our inclusion of non-English publications, and the use of our findings to communities revisiting their CWF status.

\section{What is already known on this subject?}

- Cessation of community water fluoridation (CWF) has been observed across jurisdictions, globally, and appears to be occurring with increasing frequency in some regions.

- There is no published comprehensive synthesis of research on cessation of CWF and its impact on dental caries, despite the value of such a synthesis for communities that are undertaking CWF decision-making.

\section{What this study adds?}

- Research on the impact of CWF cessation on dental caries is limited in quantity, diverse in context (time and place), and variable in methodological quality.

- Overall, the research points to an increase in dental caries (tooth decay) post-CWF cessation; however, that effect is not uniform or inevitable.

- To build the evidence base, it is important to exploit the research opportunity provided by cessation, using rigorous methods.

- There is virtually no published research on: the impact of CWF cessation on the distribution of dental caries (ie, is it equitable or not); the decision-making circumstances around CWF cessation; and the viability and cost-effectiveness of alternative fluoride delivery mechanisms postcessation, in different contexts. 
Acknowledgements The authors are grateful to Dr Diane Lorenzetti for her assistance with the literature search. They also thank Ms Salima Thawer for her assistance with extraction and preparation of data for the quantitative synthesis. LM acknowledges an Applied Public Health Chair award funded by the Canadian Institutes of Health Research (Institute of Population and Public Health, and Institute of Musculoskeletal Health and Arthritis), the Public Health Agency of Canada, and Alberta Innovates-Health Solutions.

Contributors LM contributed to the conceptualisation of the study and to the analysis and interpretation of data. She led the writing of the manuscript. SS contributed to the conceptualisation of the study and to the analysis and interpretation of data. She provided critical input to the writing of the manuscript.

Funding Canadian Institutes of Health Research (Institute of Population and Public Health, and Institute of Musculoskeletal Health and Arthritis), the Public Health Agency of Canada, and Alberta Innovates - Health Solutions (Applied Public Health (hair award).

Competing interests None declared.

Provenance and peer review Not commissioned; externally peer reviewed.

Open Access This is an Open Access article distributed in accordance with the Creative Commons Attribution Non Commercial (CC BY-NC 4.0) license, which permits others to distribute, remix, adapt, build upon this work non-commercially, and license their derivative works on different terms, provided the original work is properly cited and the use is non-commercial. See: http://creativecommons.org/ licenses/by-nc/4.0/

\section{REFERENCES}

1 Burt BA, Eklund SA. Dentistry, dental practice, and the community. 5th edn. Philadelphia, PA: W.B. Saunders Col, 1999.

2 Rose G. The strategy of preventive medicine. Oxford: Oxford University Press, 1992.

3 McLaren L, Mclntyre L, Kirkpatrick S. Rose's population strategy of prevention need not increase social inequalities in health. Int J Epidemiol 2010;39:372-7.

4 McDonagh $\mathrm{M}$, Whiting $\mathrm{P}$, Bradley $\mathrm{M}$, et al. A systematic review of public water fluoridation. York: NHS Centre for Reviews and Dissemination. University of York, 2000. (Report 18).

5 Iheozor-Ejiofor Z, Worthington HV, Walsh T, et al. Water fluoridation for the prevention of dental caries. Cochrane Database Syst Rev 2015;6:CD010856.

6 [No authors]. Understanding public decision-making on community water fluoridation. J Can Dent Assoc 2013;79:d77.

7 Rabb-Waytowich D. Water fluoridation in Canada: past and present. J Can Dent Assoc 2009;75:451-4.

8 Liberati A, Altman DG, Tetzlaff J, et al. The PRISMA Statement for reporting systematic reviews and meta-analyses of studies that evaluate health care interventions: explanation and elaboration. PLOS Med 2009;6:e1000100.

9 Connett P, Beck J, Micklem HS. The case against fluoride. White River Junction, VT: Chelsea Green Publishing Company, 2010.

10 Cochrane Handbook for Systematic Reviews of Interventions. Chapter 16: Special Topics in Statistics; Section 16.1.3.2: Imputing standard deviations for changes from baseline. http://handbook.cochrane.org/ (accessed 24 Mar 2016).

11 Bax L: MIX2.0_-Professional software for meta-analysis in Excel. Version 2.0.1.4. BiostatXL, 2011. http://www.meta-analysis-made-easy.com

12 Borenstein M, Hedges LV, Higgins JPT, et al. Introduction to meta-analysis. Chichester, UK: John Wiley \& Sons, Ltd, 2009.

13 Cochrane Handbook for Systematic Reviews of Interventions. Chapter 7: Selecting studies and collecting data; Section 7.7.3.8: Combining groups (includes Table 7.7.a: formulae for combining groups). http://handbook.cochrane.org/ (accessed 24 Mar 2016).

14 Cho HJ, Jin BH, Park DY, et al. Systemic effect of water fluoridation on dental caries prevalence. Community Dent Oral Epidemiol 2014;42:341-8. *

15 Seppä L, Hausen H, Kärkkäinen S. Plaque fluoride and mutans streptococci in plaque and saliva before and after discontinuation of water fluoridation. Eur J Oral Sci 1996;104Pt 1):353-8.*

16 Seppä L, Kärkkäinen S, Hausen H. Caries frequency in permanent teeth before and after discontinuation of water fluoridation in Kuopio, Finland. Community Dent Oral Epidemiol 1998;26:256-62.*

17 Seppä L, Kärkkäinen S, Hausen H. Caries in the primary dentition, after discontinuation of water fluoridation, among children receiving comprehensive dental care. Community Dent Oral Epidemiol 2000;28: 281-8. ${ }^{*}$

18 Seppä L, Kärkkäinen S, Hausen H. Caries trends 1992-1998 in two low-fluoride Finnish towns formerly with and without fluoridation. Caries Res 2000;34: 462-8.*

19 Maupomé G, Clark DC, Levy SM, et al. Patterns of dental caries following the cessation of water fluoridation. Community Dent Oral Epidemiol 2001;29:37-47.*
20 Maupomé G, Shulman JD, Clark DC, et al. Tooth-surface progression and reversal changes in fluoridated and no-longer fluoridated communities over a 3-year period. Caries Res 2001;35:95-105. *

21 Maupomé G, Schulman JD, Clark DC, et al. Socio-demographic features and fluoride technologies contributing to higher fluorosis scores in permanent teeth of Canadian children. Caries Res 2003;37:327-34.*

22 Clark DC, Schulman JD, Maupomé G, et al. Changes in dental fluorosis following the cessation of water fluoridation. Community Dent Oral Epidemiol 2006;34:197-204.*

23 Thomas FD, Kassab JY, Jones BM. Fluoridation in Anglesey 1993: a clinical study of dental caries in 5-year-old children who had experienced sub-optimal fluoridation. Br Dent J 1995;178:55-9.*

24 Hulse $\mathrm{G}$, Kenrick $A$, Thomas $\mathrm{CH}$, et al. Welsh water should reinstate fluoridation on Anglesey. Br Dent J 1995;178:46-7.*

25 Kunzel W, Fisher T. Rise and fall of caries prevalence in German towns with different fluoride concentrations in drinking water. Caries Res 1997;31:166-73. * (note: this paper includes the periods of interruption and cessation. For data extraction we focused only on the cessation period).

26 Kunzel W, Fisher $T$, Lorenz $R$, et al. Decline of caries prevalence after the cessation of water fluoridation in the former East Germany. Community Dent Oral Epidemiol 2000;28:382-9.*

27 Kunzel W, Fischer T. Caries prevalence after cessation of water fluoridation in La Salud, Cuba. Caries Res 2000;34:20-5.*

28 Lekesova I. [Fluorine in the prevention of dental caries]. Cas Lek Cesk 1998;137:201-6. *

29 Lekesova I, Rokytova K, Salandova M, et al. Zastaveni fluoridace pitne vody v Praze. "Discontinuance of fluoridation of drinking water in Prague Changes in the health system and oral health of school children". * Progresdent 1996;6:15-17.

30 Nobre dos Santos M, Cury JA. Dental plaque fluoride is lower after discontinuation of water fluoridation. Caries Res 1988;22:316-17.*

31 Attwood D, Blinkhorn AS. Trends in dental health of ten-year-old school children in south-west Scotland after cessation of water fluoridation. Lancet 1988;2:266-7. *

32 Attwood D, Blinkhorn AS. A reassessment of the dental health of urban Scottish schoolchildren following the cessation of water fluoridation. Community Dent Health 1989;6:207-14. *

33 Attwood D, Blinkhorn AS. Reassessment of the effect of fluoridation on cost of dental treatment among Scottish schoolchildren. Community Dent Oral Epidemiol 1989;17:79-82.*

34 Attwood D, Blinkhorn AS. Dental health in schoolchildren 5 years after water fluoridation ceased in south-west Scotland. Int Dent J 1991; 41:43-8.*

35 Gu XS, Shen YM. [Effects of stopping water fluoridation on prevalence of dental caries in children]. Zhonghua Yu Fang Yi Xue Za Zhi 1989;23:346-8. *

36 Wei Z-D, Wei Y. Fluoridation in China: a clouded future. Fluoride 2002; $35: 1-4$. *

37 Stephen KW, McCall DR, Tullis J. Caries prevalence in northern Scotland before, and 5 years after, water defluoridation. Br Dent J 1987;163:324-6. *

38 Kalsbeek H, Kwant GW, Groeneveld A, et al. [Cessation of fluoridation in drinking water; results of caries research in Tiel and Culemborg in the period of 1968-1988]. Ned Tijdschr Tandheelkd 1992;99:24-8.*

39 Kalsbeek H, Kwant GW, Groenveld A, et al. Caries experience of 15-year-old children in The Netherlands after discontinuation of water fluoridation. Caries Res 1993:27:201-5. *

40 Kobayashi S, Kawasaki K, Takagi O, et al. Caries experience in subjects 18-22 years of age after 13 years' discontinued water fluoridation in Okinawa. Community Dent Oral Epidemiol 1992;20:81-3. *

41 Lemke CW, Doherty JM, Arra MC. Controlled fluoridation: the dental effects of discontinuation in Antigo, Wisconsin. J Am Dent Assoc 1970;80: 782-6.*

42 Jordan W. The Austin school health study. Dental Health. Am J Public Health 1962;52:301.*

43 World Health Organization (WHO). Oral health surveys: basic methods. 5th edn Geneva: World Health Organization, 2013.

44 Burt BA. Prevention policies in light of the changed distribution of dental caries Acta Odontol Scand 1998;56:179-86.

45 Fortin N, Green DA, Lemieux T, et al. Canadian inequality: recent developments and policy options. Can Public Policy 2012;38:121-45.

46 Easley MW. Dental public health practice: political science meets health science-a case study in successful technology transfer. J Theory Practice Dent Public Health 2013;1:15-18.

47 Burt BA, Petterson EO. Fluoridation: developments in Sweden. Br Dent $J$ 1972;133:57-9. 